\title{
Peripheral Nerve Injury to the Lower Limb: Repair and Secondary Reconstruction
}

\author{
Mukund R. Thatte ${ }^{1} \quad$ Amita Hiremath ${ }^{1} \quad$ Mayur S. Goklani ${ }^{1} \quad$ Neehar R. Patel $^{1} \quad$ Anupam B. Takwale $^{1}$ \\ ${ }^{1}$ Department of Plastic Surgery, Bombay Hospital and Medical \\ Research Centre, Mumbai, Maharashtra, India \\ Address for correspondence Mukund R. Thatte, MS (Gen), MCh (Plastic), \\ Department of Plastic Surgery, Bombay Hospital and Medical research \\ Centre, Mumbai 400020, Maharashtra, India (e-mail: mthatte@gmail.com).
}

Indian J Plast Surg 2019;52:93-99

\begin{abstract}
This article is based on literature review of relevant articles as well as the authors' own experiences in treating peripheral nerve injuries of the lower limb. The article Keywords

- lower limb nerve injury

- peroneal nerve

- poor prognosis deals with causative factors of lower limb nerve injuries, various grading systems of the injuries, approaches to such injuries, and techniques to repair lower limb nerve injuries. It also enumerates several reasons to explain the poorer prognosis of peroneal nerve injuries and the possible distal nerve transfers in lower limb albeit with poorer outcomes.
\end{abstract}

\section{Introduction}

The lower limb gets its peripheral nerves from L2 to S2 levels of the spinal cord through the lumbosacral plexus. These nerves are involved in injury in a multitude of ways. This article is based on literature review of relevant articles as well as the authors' own experience in treating these injuries.

\section{Anatomy}

The nerves of the lower limb originate from L2 to S2 spinal levels forming the lumbosacral plexus that gives rise to the nerves ( - Fig. $\mathbf{1}$ ).

The major nerves are

1. Femoral nerve

2. Obturator nerves

3. Sciatic nerve and its components tibial and common peroneal nerve (CPN)

Pure sensory nerves are

1. Lateral cutaneous nerve of the thigh (LCNT)

2. Saphenous nerve

3. Sural nerve

\section{Incidence}

There are several large studies on traumatic nerve injuries. ${ }^{1,2}$ The frequency of the lower extremity nerve injuries is assessed to approximately 20 to $23 \%$ of the overall lesions to the peripheral nerve system. Peroneal division neuropathy is the most common lower extremity nerve palsy.

\section{Etiology of Injury}

There are various ways in which the lower limb nerves are injured. Some of the common etiology is listed as follows:

1. Fractures, particularly the hip, femur, tibia, fibula, and, occasionally, the ankle

2. Crush injury

3. Knife assault

4. Gunshot

5. Iatrogenic

6. Traction

7. Blunt trauma

8. Radiation

Iatrogenic injuries form a significant portion of injuries. They are caused by

1. Intramuscular injection

2. Total hip prosthesis operation

3. Excision of tumor

4. Tourniquet

5. Traction or pressure during operation

Prof. Kretschmer et $\mathrm{al}^{3}$ have written a detailed article on iatrogenic injury to peripheral nerves. One hundred twenty-six (17.4\%) of the 722 surgically treated cases were iatrogenic in origin. Most of these injuries occurred during a previous operation. 


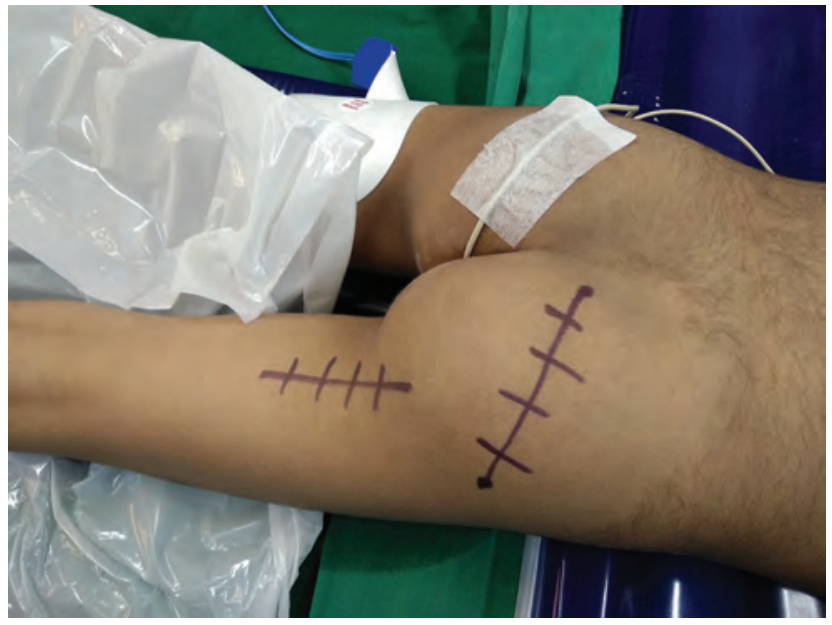

Fig. 1 Incisions showing the Socolovsky approach.

In other studies nerve referral centers estimate similar rates among the traumatic injuries they operate on. Approximately 25\% (89/353) of the largest series of operated sciatic nerve lesions ${ }^{4}$ and 50\% (47/94) of femoral nerve lesions seen ${ }^{5}$ were iatrogenic in nature.

The main causes of iatrogenic injuries in lower limb are

1. Femoral nerve during hernia surgery

2. Peroneal and saphenous nerve during varicose vein surgery. Peroneal nerve during fracture fixation proximally and distally

3. Sciatic nerve by intramuscular (IM) injection especially in children and during hip arthroplasty and femoral osteosynthesis either due to traction or the cement or the trauma of the fracture itself, further aided by callus engulfing the nerve, in which case it cannot really be called iatrogenic.

\section{Approach to Lower Limb Nerve Injury}

A complete clinical examination with detailed history and full neurologic testing usually points clearly to the nerve involved. In the case of the sciatic nerve injury, it is important to note the level-at or just distal to the notch (typically injection palsy), mid-thigh (typically fracture femur or assault), and lower than that. It is important to check (a) hamstring function particularly biceps femoris, (b) gastrocnemius soleus and tibialis posterior, (c) tibialis anterior and extensor digitorum and hallucis, and (d) sensation in the foot. This will point to the level and extent of the injury ( $\mathbf{-}$ Tables $\mathbf{1}$ and $\mathbf{2}$ ).

\section{Investigations}

1. 3T magnetic resonance imaging (MRI) ${ }^{6}$ : It can give excellent visualization.

2. Musculoskeletal ultrasonography: It is also good and less expensive than MRI.

3. Electrodiagnostics (EDx).

MRI and ultrasonography (USG) help delineate the site of lesion and extent of physical lesion. EDx will help determine severity, type of lesion, reinnervation, if any, and differentiate neuropraxia from axonotmesis.

Table 1 The LSUHSC grading system for buttock or tight-level tibial division lesions ${ }^{4}$

\begin{tabular}{|l|l|}
\hline Grade & Criteria \\
\hline 0 & No gastrocnemius-soleus function; no inversion; no toe flexion; little or no sensation on the plantar surface of the foot \\
\hline 1 & Trace gastrocnemius, but no other tibially innervated muscle function; trace to poor plantar sensation \\
\hline 2 & Gastrocnemius contracts vs. gravity only; plantar surface sensation usually $\leq$ grade 2 \\
\hline 3 & Gastrocnemius-soleus contracts vs. gravity and some force; trace or better inversion; plantar sensation $\leq$ grade 3 \\
\hline 4 & Gastrocnemius contracts vs. moderate resistance; inversion $\geq$ grade 3 ; either a trace or no toe flexion; sensation $\geq$ grade 4 \\
\hline 5 & Gastrocnemius has full function; inversion $\geq$ grade 4 ; toe flexion present; plantar sensation $\geq$ grade 4 \\
\hline
\end{tabular}

Abbreviation: LSUHSC, Louisiana State University Health Sciences Center.

Table 2 The LSUHSC grading system for buttock or tight-level peroneal division lesions ${ }^{4}$

\begin{tabular}{|c|c|}
\hline Grade & Criteria \\
\hline 0 & No or little function in short head of biceps; no peroneally innervated muscle function; no AT, EHD, or ED function \\
\hline 1 & Short head of the biceps contracts; no distal peroneally innervated muscle function \\
\hline 2 & $\begin{array}{l}\text { Short head of the biceps contracts; peroneally innervated muscles contract vs. gravity or better; no trace of AT; no } \\
\text { other distal motor function }\end{array}$ \\
\hline 3 & $\begin{array}{l}\text { Short head of the biceps contracts; peroneally innervated muscles } \geq \text { grade } 3 \text {; AT contracts vs. gravity, but function of } \\
\text { EHD and ED for toes usually absent }\end{array}$ \\
\hline 4 & $\begin{array}{l}\text { Short head of the biceps and peroneally innervated muscles contract, as does AT, which is } \geq \text { grade } 3 \text {; EHD and ED } \\
\text { may have trace function }\end{array}$ \\
\hline 5 & $\begin{array}{l}\text { Short head of the biceps and peroneally innervated muscles contract, as does AT, which is } \geq \text { grade } 4 \text {; EHD and ED } \\
\text { contract, at least vs. gravity }\end{array}$ \\
\hline
\end{tabular}

Abbreviations: AT, anterior tibialis; ED, extensor digitorum; EHD, extensor hallucis longus; LSUHSC, Louisiana State University Health Sciences Center. 


\section{Nerve Repair}

The techniques used include the following:

1. Neurolysis under magnification

2. End to end repair

3. Nerve grafting

4. Nerve Transfers

5. Nerve decompression

Exposure at buttock level: The author would highly recommend Prof. Mariano Socolovsky's technique of buttock level exposure. See - Figs. 1-3. Details are available in his paper. ${ }^{7}$ For thigh and knee levels standard exposure is simple and straightforward.

1. Neurolysis under magnification: Commonly used in injection palsy ${ }^{8}$ where one can find an area of swelling and petechiae in the sciatic trunk. It is useful to open the epineurium under full magnification and release the fascicles. Stimulation intraoperatively before and after the lysis is a useful guide to determine if this has helped. If an area of fascicle destruction and fibrosis is noted, selective excision of concerned fascicles and end-to-end repair or grafting (in case gap is too

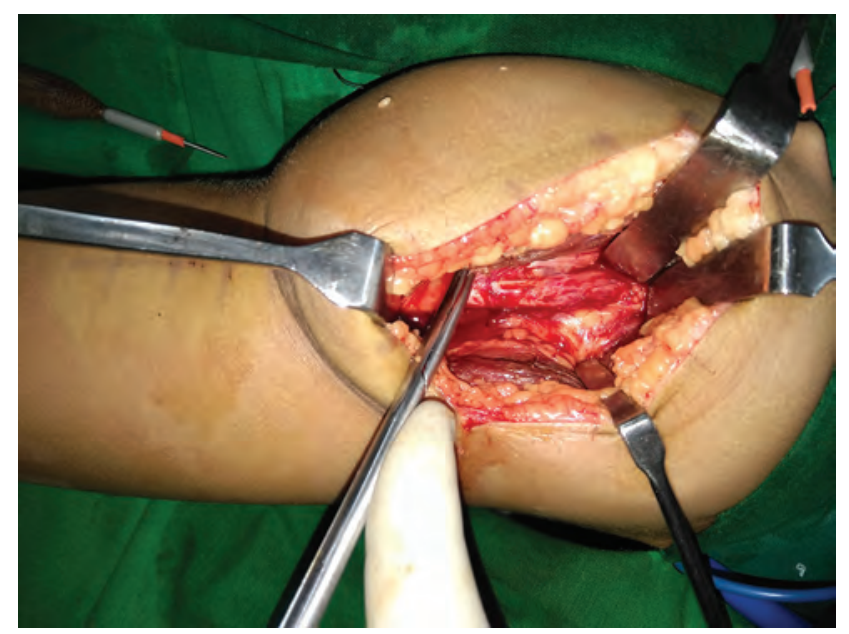

Fig. 2 Partly intact sciatic nerve.

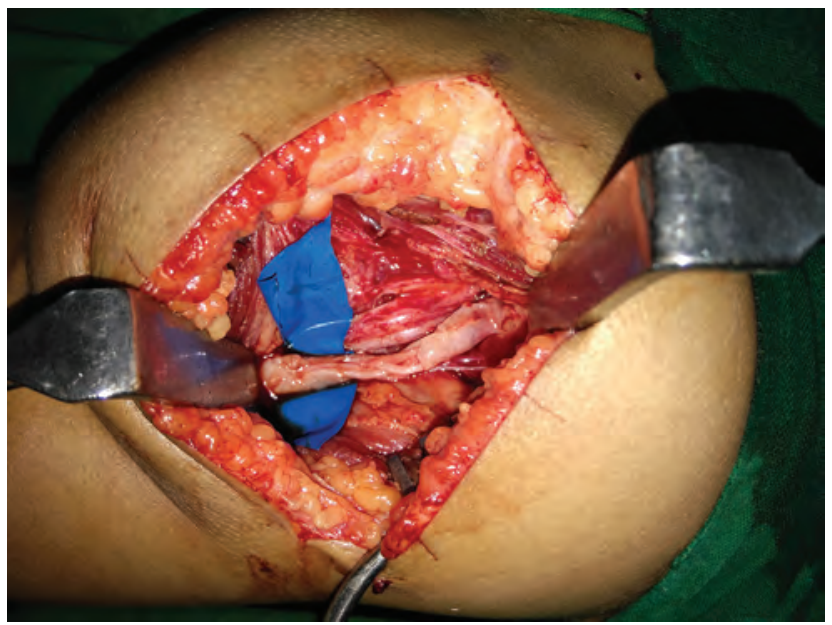

Fig. 3 Nerve graft across peroneal component. large) is recommended. It is important to maintain the integrity of unaffected fascicles-usually of the tibial division.

In our experience, the same technique is useful in cases in which the sciatic nerve is encased within a callus in the midthigh level following a fracture shaft femur. It is important to know functional parts of the distal nerve preoperatively by clinical examination and EDx.

2. End-to-end repair: Typically used in cases of assault where the nerve is sharply divided by a plunging knife. This is feasible within the first few weeks. Later the nerve is likely to end up with fibroses and retract, leading to the need for nerve grafts (-Figs. 4-10).

3. Nerve grafts: How much can one pull two ends together? This is the question. The author first debrides the two ends until healthy sprouting axons are seen. Both side nerve trunks are then atraumatically mobilized while trying to keep segmental blood supply intact. After this is achieved, if a 6-0 nylon suture through the epineurium can hold the nerve ends together while the limb is in neutral position without abnormal joint movement, then it is suitable for end-to-end repair. If not, then nerve grafts are used. Typical donor is the ipsilateral sural nerve (-Figs. 11-13).

4. Nerve transfers: Unlike the upper limb where nerve transfers are very common and done frequently, the lower limb has far fewer established techniques for nerve transfers and they are not commonly used. A few examples are cited in the following text.

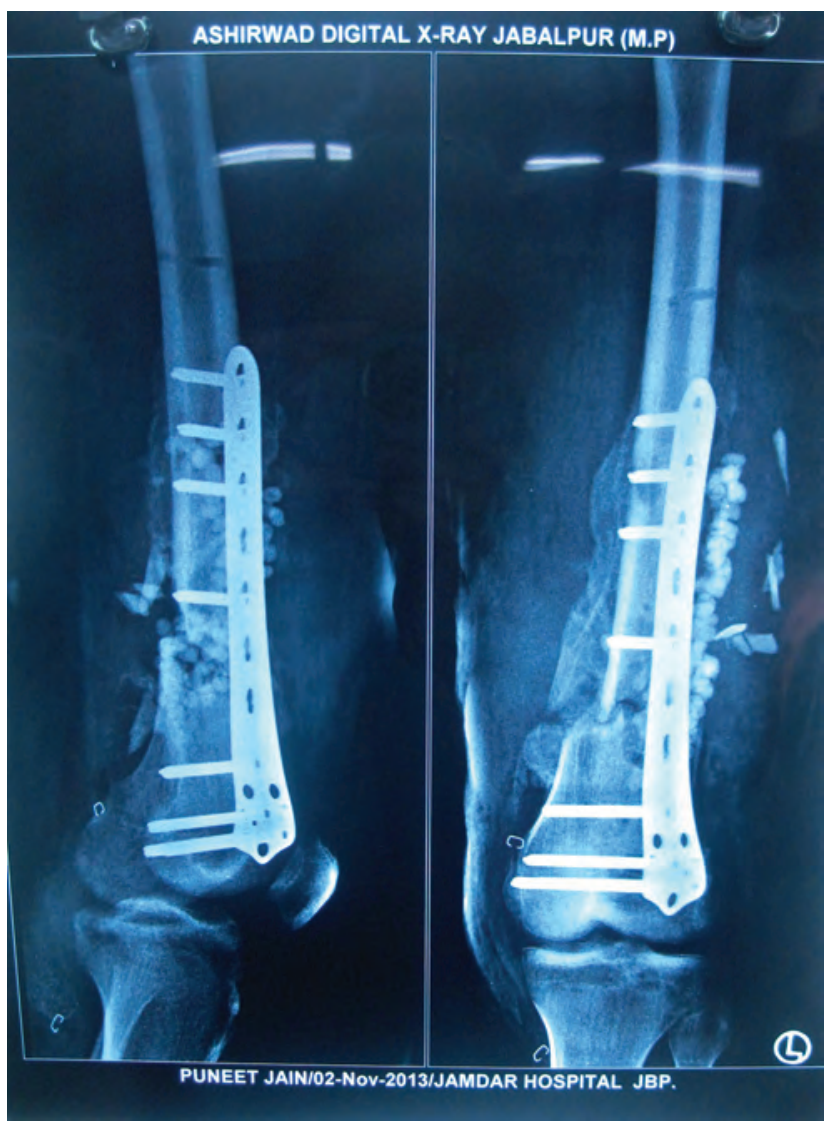

Fig. 4 X-ray showing fracture femur. 


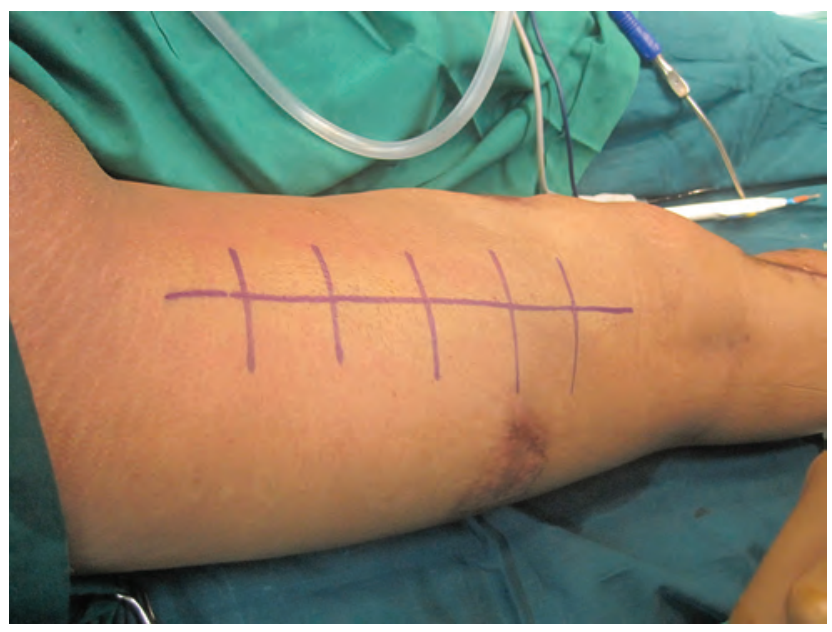

Fig. 5 Incision for exposure.

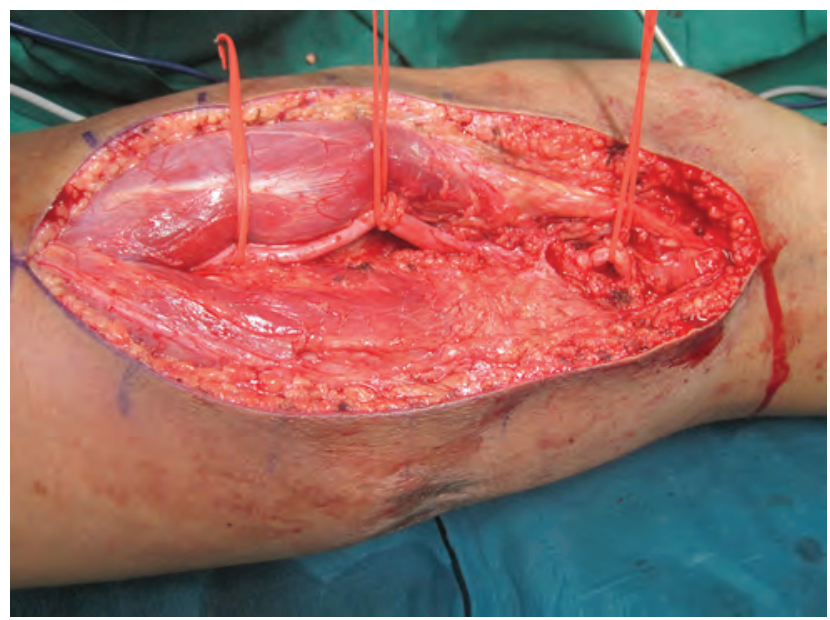

Fig. 6 Nerve injured and stuck in callus.

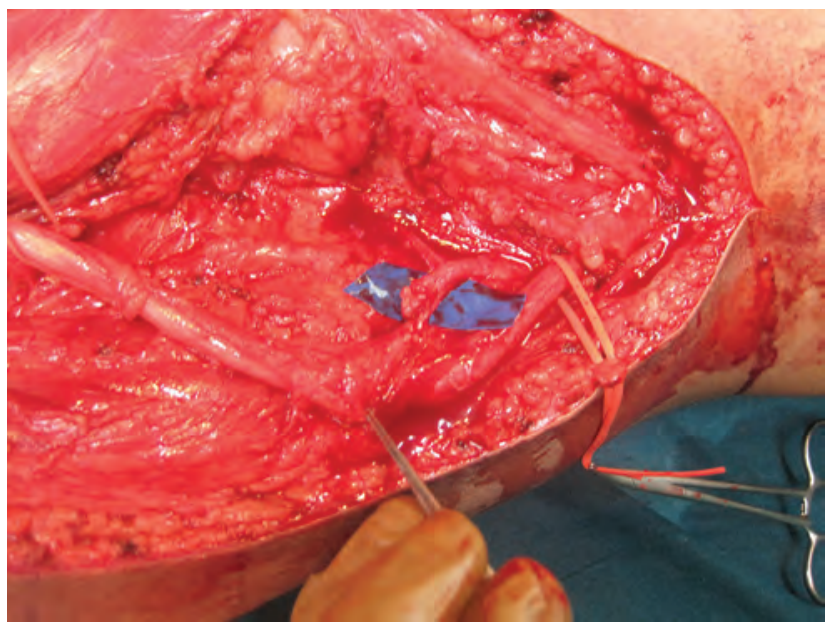

Fig. 7 Partial injury to peroneal division.

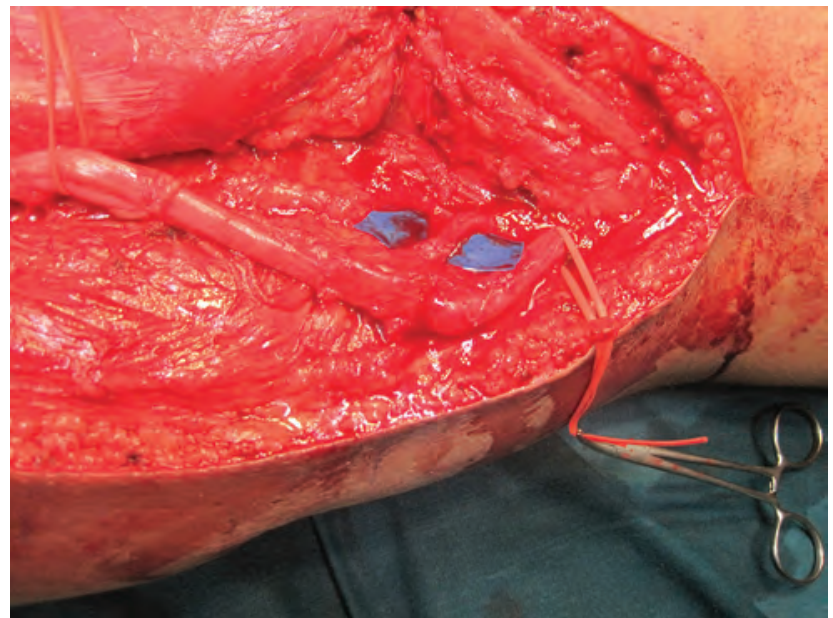

Fig. 8 End-to-end repair of peroneal division.

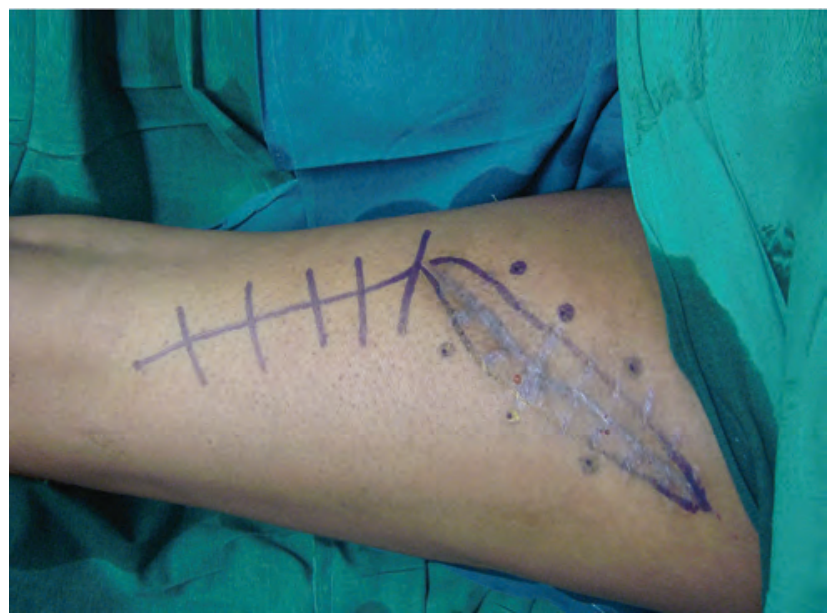

Fig. 9 Old stab wound and incision for exploration.

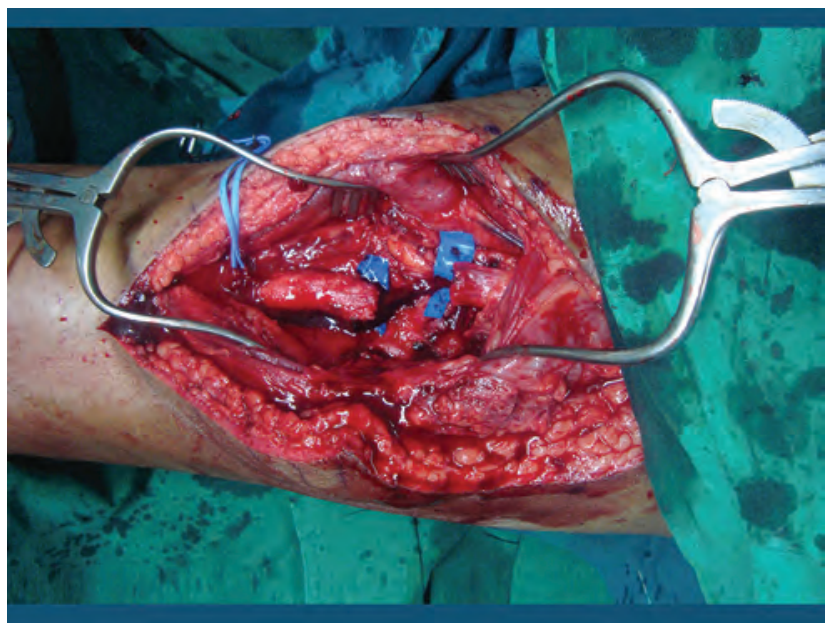

Fig. 10 Two healthy nerve ends ready for repair. 


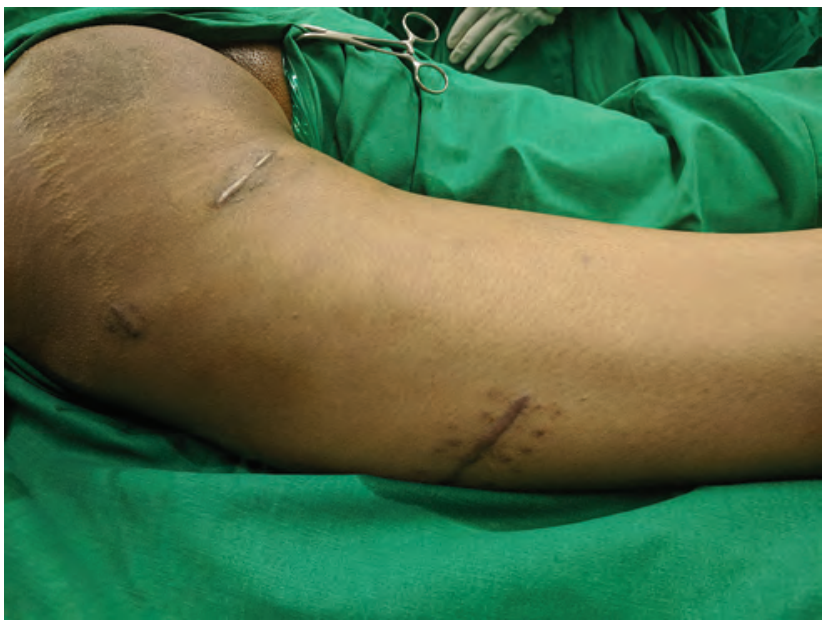

Fig. 11 Multiple stab wounds.

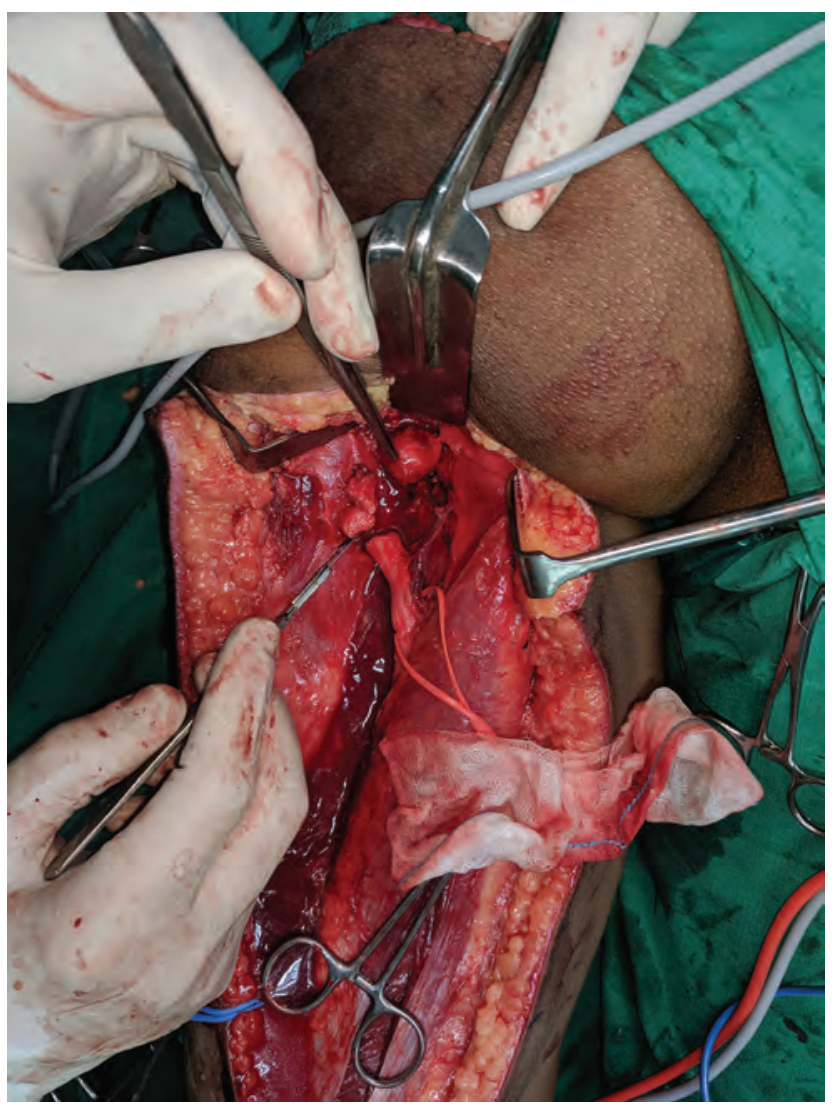

Fig. 12 Showing two ends with gap.

5. Nerve compression: The peroneal nerve at the neck of Fibula can be compressed with a cyst/ ganglion needed decompression. Diagnosis is made with MRI/ EDx. In author's experience, a tight closure after ALT flap led to a femoral nerve palsy and was relieved by decompression at the inguinal level ( - Figs. 14 and 15 ).

Nerve Transfers in lower limb: In the clinical space there are two instances. ${ }^{9,10}$ In case of neuroma of superficial peroneal

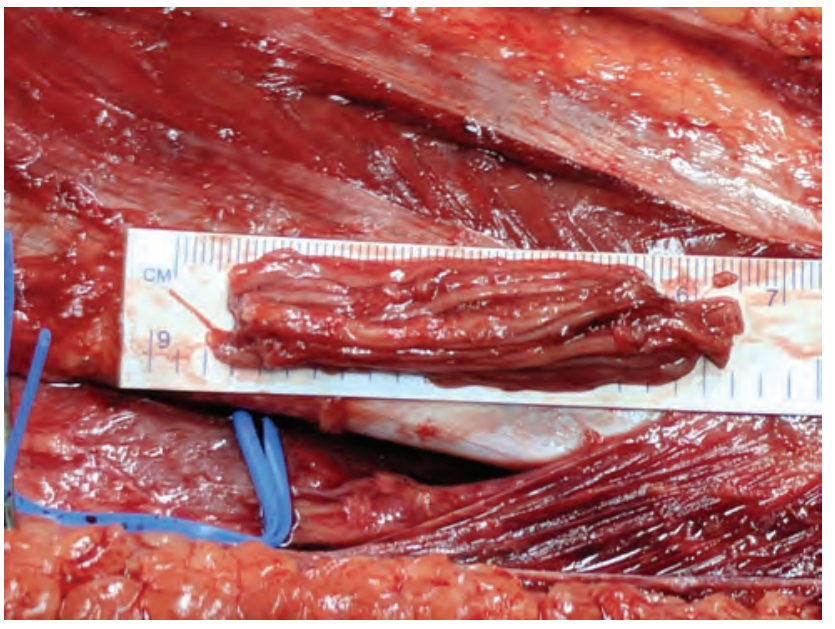

Fig. 13 Grafts ready for repair.

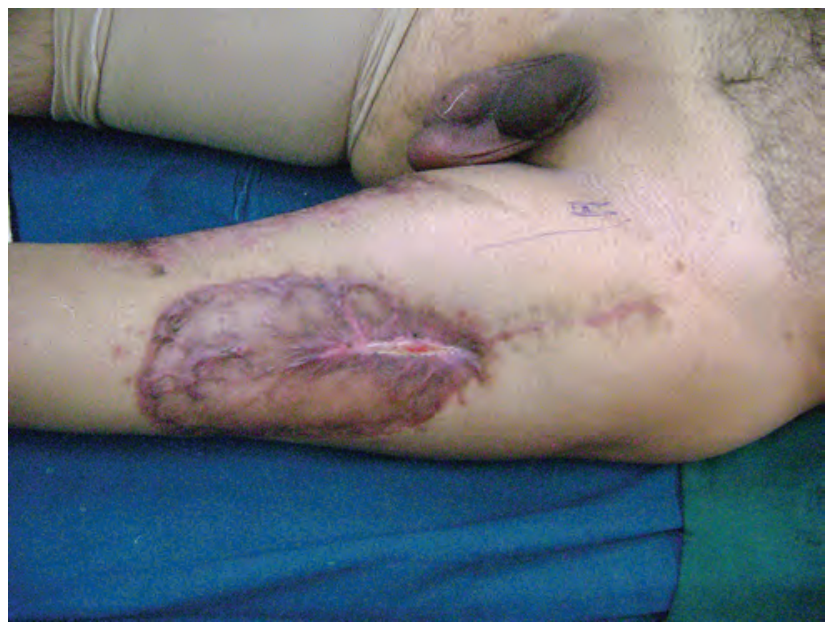

Fig. 14 Post ALT compressive neuropathy of femoral nerve.

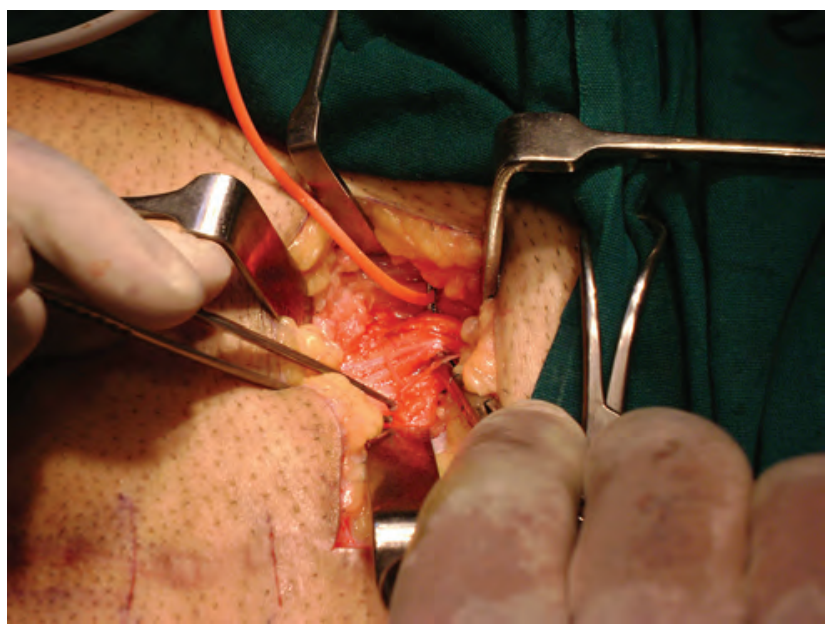

Fig. 15 Decompressed femoral nerve.

nerve at ankle level during ankle arthrodesis surgery, a transfer of the superficial to the deep peroneal nerve with conduit or allograft is described to alleviate pain. 
In cases of complete palsy of sciatic, transfer of distal motor branches of the femoral nerve to the quadriceps muscles are transferred to branches to gastrocnemius along with transfer of saphenous nerve to sural nerve for sensation. Results show $3+$ power of ankle flexion and improved ambulation.

Experimentally, ${ }^{11,12}$ contralateral L6 root has been transferred to ipsilateral L6 root both in rats and Rhesus monkeys with encouraging results.

In cadavers an investigation was done ${ }^{13}$ to determine transfers from tibial to peroneal division. The most suitable pairs were

1. For tibialis anterior either nerve to lateral gastrocnemius or nerve to popliteus

2. For extensor hallucis longus (EHL), nerve to flexor hallucis longus (FHL)

In a personal communication, Prof. Bertelli who is an acknowledged expert in nerve transfers had the following to say "I have done Gracilis motor branch to Sciatic, Quadriceps medial head motor branch to Peroneal nerve, branch to Soleus to Tibialis anterior motor branch, branch to Gastrocnemius to Tibialis anterior, branch to FHL to tibial anterior motor branch and free Gracilis innervated by Quadriceps motor branch. All this with unsatisfactory results, if any. Some recovery I got by transferring the Abductor Hallucis motor branch for reinnervation of Extensor Digitorum Brevis muscle. I am, in general, disappointed with nerve transfers in the lower limb."

\section{Peroneal Nerve}

The peroneal nerve deserves special mention because it is often the peroneal division that is affected more in a sciatic injury and because it has a poorer prognosis unless detected early and treated aggressively. There has been a lot of discussion about why the peroneal nerve is different. Some of the reasons (1-4 below) are discussed by Immerman et a $1^{14}$ as well as Cush and Irgit, ${ }^{15}$ and Giuffre et al, ${ }^{16}$ reasons 5-7 are from the Louisiana group ${ }^{16}$ and $8-10$ are the authors' own experience:

1. The peroneal nerve is tethered at two places, proximally in the greater sciatic notch and distally where it passes through fibrous tunnel around the knee.

2. This anatomic feature limits potential mobility to $0.5 \mathrm{~cm}$.

3. It also has less connective tissue and fewer and larger fascicles than the tibial division.

4. The distance to reinnervation of key muscle groups is longer than that for the tibial nerve.

5. The tibial nerve has a better blood supply and regeneration.

6. The tibial nerve has a higher force-absorbing fascicle/ connective tissue count than the CPN.

7. The tibial nerve-innervated gastrocnemius soleus requires less reinnervation for functional contraction than deep peroneal branches, which innervate long, thin extensor muscles at multiple sites and require coordinated nerve input for effective contraction.
8. At the point of classical IM injection in buttocks, it is more superficial or lateral than the tibial division.

9. In cases of fractures around the proximal tibial fibula, the peroneal has no escape when the neck of fibula fractures.

10. If there is additional compartment syndrome, the anterior compartment is much tighter and therefore muscle damage is more common.

As a result, the peroneal division is injured more frequently, and recovery is often worse than for the tibial division.

\section{Results in Sciatic nerve Surgery}

A comprehensive review from The Louisiana State University of 806 cases operated for sciatic Nerve injury ${ }^{17}$ shows that acute lacerations undergoing suture repair were best for the thigh-then-buttock-level tibial (93\%/73\%) and then same-level common peroneal divisions (69\%/30\%); at the knee level, tibial outcomes (100\%) were better than those for the common peroneal nerve (CPN) (84\%). Secondary graft repairs for lacerations had good outcomes for the thigh-then-buttock-level tibial $(80 \% / 62 \%)$, followed by common peroneal divisions at the same levels (45\%/24\%). The knee/leg-level tibial nerve (94\%) did better than the CPN (40\%) here. In-continuity lesions with positive intraoperative nerve action potentials underwent neurolysis with better results for the thigh-then-buttock-level tibial division (95\%/86\%) than for same-level CPN (78\%/69\%). The knee/leg-level tibial nerve did better than the CPN (95\%/93\%).

\section{Conclusions}

Lower limb nerve injuries must be treated early to get good results. Tibial division does better than peroneal. Best results are at knee level followed by thigh level and finally at buttock level. Iatrogenic injuries are more common than one would imagine.

\section{Conflict of Interest}

None declared.

\section{References}

1 Gosk J, Rutowski R, Rabczyński J. The lower extremity nerve injuries-own experience in surgical treatment. Folia Neuropathol 2005;43(3):148-152

2 Eser F, Aktekin LA, Bodur H, Atan C. Etiological factors of traumatic peripheral nerve injuries. Neurol India 2009;57(4):434-437

3 Kretschmer T, Antoniadis G, Braun V, Rath SA, Richter HP. Evaluation of iatrogenic lesions in 722 surgically treated cases of peripheral nerve trauma. J Neurosurg 2001;94(6):905-912

4 Kim DH, Murovic JA, Tiel R, Kline DG. Management and outcomes in 353 surgically treated sciatic nerve lesions. J Neurosurg 2004;101(1):8-17

$5 \mathrm{Kim}$ DH, Kline DG. Surgical outcome for intra- and extrapelvic femoral nerve lesions. J Neurosurg 1995;83(5):783-790

6 Soldatos T, Andreisek G, Thawait GK, et al. High-resolution 3-T MR neurography of the lumbosacral plexus. Radiographics 2013;33(4):967-987 
7 Socolovsky M, Garategui L, Campero A, Conesa H, Basso A. Exposure of the sciatic nerve in the gluteal región without sectioning the gluteus maximus: An anatomical and microsurgical study. Acta Neurochir (Wien) 2010;108:233-240

8 Topuz K, Kutlay M, Simşek H, Atabey C, Demircan M, Senol Güney M. Early surgical treatment protocol for sciatic nerve injury due to injection-a retrospective study. $\mathrm{Br} \mathrm{J}$ Neurosurg 2011;25(4):509-515

9 Bibbo C, Rodrigues-Colazzo E, Finzen AG. Superficial peroneal nerve to deep peroneal nerve transfer with allograft conduit for neuroma in continuity. J Foot Ankle Surg 2018;57(3):514-517

10 Moore AM, Krauss EM, Parikh RP, Franco MJ, Tung TH. Femoral nerve transfers for restoring tibial nerve function: an anatomical study and clinical correlation: a report of 2 cases. J Neurosurg 2018;129(4):1024-1033

11 Zheng MX, Hua XY, Jiang S, Qiu YQ, Shen YD, Xu WD. Contralateral peripheral neurotization for a hemiplegic hindlimb after central neurological injury. J Neurosurg 2018;128(1):304-311
12 Lin H, Chen A, Hou C. Contralateral L-6 nerve root transfer to repair lumbosacral plexus root avulsion: experimental study in rhesus monkeys. J Neurosurg 2013;119(3):714-719

13 White CP, Cooper MJ, Bain JR, Levis CM. Axon counts of potential nerve transfer donors for peroneal nerve reconstruction. Can J Plast Surg 2012;20(1):24-27

14 Immerman I, Price AE, Alfonso I, Grossman JA. Lower extremity nerve trauma. Bull Hosp Jt Dis (2013) 2014;72(1):43-52

15 Cush G, Irgit K. Drop foot after knee dislocation: evaluation and treatment. Sports Med Arthrosc Rev 2011;19(2):139-146

16 Giuffre JL, Bishop AT, Spinner RJ, Levy BA, Shin AY. Partial tibial nerve transfer to the tibialis anterior motor branch to treat peroneal nerve injury after knee trauma. Clin Orthop Relat Res 2012;470(3):779-790

17 Murovic JA. Lower-extremity peripheral nerve injuries: a Louisiana State University Health Sciences Center literature review with comparison of the operative outcomes of 806 Louisiana State University Health Sciences Center sciatic, common peroneal, and tibial nerve lesions. Neurosurgery 2009;65(4 Suppl):A18-A23 